\title{
En recuerdo de la Arquitecta Angela Schweitzer Lopetegui
}

\author{
Euclides Guzmán Alvarez
}

\section{Filiación}

Académico de la F.A.U. de la Universidad de Chile

\section{Resumen}

Palabras en homenaje a la arquitecta Angela Schweitzer Lopetegui con motivo de su fallecimiento.

\section{Palabra clave}

Angela Schweitzer Lopetegui

\section{Abstract}

Words in tribute to the architect Angela Schweitzer Lopetegui on the occasion of his death.

\section{Key word}

Angela Schweitzer Lopetegui

Conocí a Angela Schweitzer desde que era estudiante de arquitectura en la Escuela de Arquitectura de la Universidad de Chile, ubicada en la Plaza Ercilla, en Santiago. Allí se tituló en 1952.

Hoy, cuando se destacan las muy variadas actividades y talentos que desplegó en su infatigable existencia, es oportuno recordar algunos hechos, tal vez, poco conocidos.

En esa época, año 1938, el Centro de Estudiantes de Arquitectura organizó una Escuela Nocturna para Obreros de la Construcción, que llegó a tener gran cantidad de alumnos. Me correspondió invitar a Angela Schweitzer a colaborar en esta actividad. Demostró allí desde un comienzo un entusiasmo tan grande, que se traducía en un quehacer casi diario en ese local.

No le pareció bien que se rechazaran postulantes por no saber leer ni escribir, y tomó como un desafío propio resolver ese problema. Reclutó entonces a un grupo de compañeras de estudio, dispuestas a atender de forma personalizada estos difíciles casos. Indagó en métodos de alfabetización de adultos, hasta lograr algunos resultados. 


\section{REVSTA DE

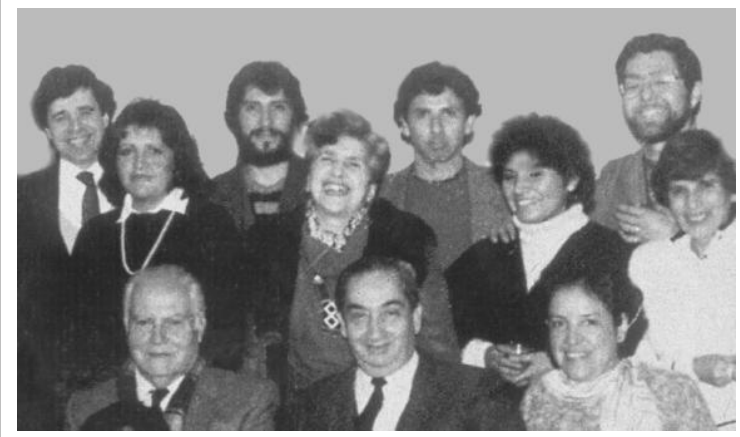

De izquierda a derecha, de pie, A.S.L. es la cuarta persona.

Un buen número de años después, cuando la Facultad de Arquitectura de la Universidad de Chile creó la Escuela de Arquitectura de Valparaíso, en 1957, a unos dos años de su inauguración, invité a Angela Schweitzer, de acuerdo con el Decano Héctor Mardones Restat, a hacerse cargo del segundo año de Taller de Diseño Arquitectónico. Otra vez constatamos la extraordinaria dedicación, seriedad y eficiencia con que tomó esta nueva actividad.

Ante el terremoto de Valdivia de 1960, no dudó en dirigirse con todos sus alumnos a colaborar en esa ciudad, no obstante las dificultades para desplazarse y permanecer en el sitio de tan grande catástrofe. Tenía el don poco común de transmitir su entusiasmo a otras personas. Ahí en Valdivia, inició con estos alumnos lo que se conoce aún como "Población Valparaíso".

Pocas veces se dan personalidades con cualidades tan relevantes.

Santiago, julio de 2002. 